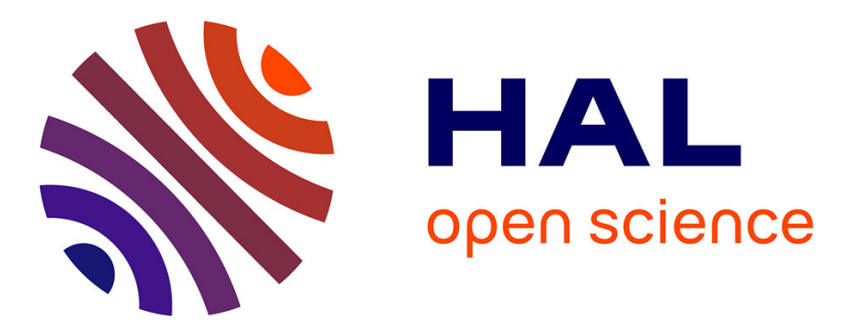

\title{
Prognostic significance of TRAIL-R1 and TRAIL-R3 expression in metastatic colorectal carcinomas.
}

Virginie Granci, Frédéric Bibeau, Andrew Krama, Florence Boissière-Michot, Simon Thézénas, Agnès Thirion, Céline Gongora, Pierre Martineau, Maguy del Rio, Marc Ychou

\section{To cite this version:}

Virginie Granci, Frédéric Bibeau, Andrew Krama, Florence Boissière-Michot, Simon Thézénas, et al.. Prognostic significance of TRAIL-R1 and TRAIL-R3 expression in metastatic colorectal carcinomas.. European Journal of Cancer, 2008, 44 (15), pp.2312-8. 10.1016/j.ejca.2008.06.042 . inserm-00318854

\section{HAL Id: inserm-00318854 https://www.hal.inserm.fr/inserm-00318854}

Submitted on 5 Sep 2008

HAL is a multi-disciplinary open access archive for the deposit and dissemination of scientific research documents, whether they are published or not. The documents may come from teaching and research institutions in France or abroad, or from public or private research centers.
L'archive ouverte pluridisciplinaire HAL, est destinée au dépôt et à la diffusion de documents scientifiques de niveau recherche, publiés ou non, émanant des établissements d'enseignement et de recherche français ou étrangers, des laboratoires publics ou privés. 
Prognostic significance of TRAIL-R1 and TRAIL-R3 expression in metastatic colorectal carcinomas.

Virginie Granci ${ }^{1^{*}}$, Frédéric Bibeau ${ }^{2^{*}}$, Andrew Kramar ${ }^{3}$, Florence Boissière-Michot ${ }^{2}$, Simon Thézénas ${ }^{3}$, Agnès Thirion $^{4}$, Céline Gongora ${ }^{1}$, Pierre Martineau ${ }^{1}$, Maguy Del Rio $^{1}$ and Marc Ychou ${ }^{4}$

${ }^{1}$ IRCM, Institut de Recherche en Cancérologie de Montpellier; INSERM, U896; Université Montpellier1; CRLC Val d'Aurelle Paul Lamarque, Montpellier, F-34298, France ; ${ }^{2}$ Service d'Anatomie Pathologique, ${ }^{3}$ Unité de Biostatistique, and ${ }^{4}$ Service d'Oncologie Digestive, Centre Régional de Lutte contre le Cancer Val d'Aurelle-Paul Lamarque, Montpellier, F-34298, France

* These authors contributed equally to the work.

To whom correspondence should be addressed:

Dr. Maguy Del Rio

IRCM, INSERM, U896

CRLC Val d'Aurelle-Paul Lamarque

208 rue des Apothicaires

34298 Montpellier Cedex 5

France

Tel: +33-467-613-745 Fax: +33-467-613-787

e-mail: $\underline{\text { mdelrio@valdorel.fnclcc.fr }}$ 


\section{ABSTRACT}

Drug resistance is believed to cause treatment failure in patients with metastatic colorectal carcinoma (CRC). Resistance to chemotherapy can involve different processes, including apoptosis, whose extrinsic pathway is regulated by expression of death-inducing TRAIL-R1 and -R2 and inhibitory TRAIL-R3 and -R4 cell surface receptors. Therefore, we investigated whether variations in their expression could influence the response to 5-Fluorouracile (5-FU) in metastatic CRC. We analysed TRAIL R-1, $-2,-3$ and -4 expression by immunohistochemistry in $\mathrm{CRC}$, using tissue micro arrays, and found that concomitant low/medium TRAIL-R1 and high TRAIL-R3 expression in primary CRC is significantly associated with a poor response to 5-FU based first line chemotherapy and with shorter progression-free survival. Specifically, the median progression-free survival was 3.1 months (poor prognostic group) vs 10.1 in the good prognostic group. Thus, the combination of TRAIL-R1 and TRAIL-R3 expression might represent a predictive and prognostic factor of the response to 5FU-based first line chemotherapy in patients with metastatic CRC.

Key words: TRAIL receptors, apoptosis, TRAIL-R1, TRAIL-R3, immuno-histochemistry, colorectal cancer; 5-FU, chemo-resistance. 


\section{Introduction.}

Tumour necrosis factor-related apoptosis-inducing ligand (TRAIL) is a type II transmembrane protein that belongs to the tumour necrosis factor (TNF) superfamily. TRAIL activates apoptosis through the death receptors TRAIL-R1 (DR4) or TRAIL-R2 (DR5/KILLER) which carry cytoplasmic death domains. TRAIL also binds to two other membrane-bound receptors, TRAIL-R3 (DcR1/TRID) and TRAIL-R4 (DcR2/TRUNDD), which can not transmit the apoptotic signal because they lack a functional intra-cytoplasmic domain. Consequently, TRAIL-R3 and TRAIL-R4 are thought to protect cells from TRAIL-induced apoptosis by acting as decoy receptors and thus interfering with the binding of the pro-apoptotic TRAILR1 and -R2. ${ }^{1}$ Importantly, unlike other TNF family members, TRAIL kills a wide variety of tumour cells with limited effects on normal tissues in vivo. ${ }^{2,3}$ This finding has aroused a great interest in the development of TRAIL targeted-therapies and currently several clinical trials are been carried out in cancer patients. ${ }^{4,5}$

Colorectal cancer (CRC) is the second most frequent cause of cancer death in Europe and United States. Chemotherapeutic agents can improve survival in patients with CRC, and 5Fluorouracile (5-FU)-based chemotherapy, modulated with folinic acid, has long been a standard regimen. To enhance its efficiency in CRC patients, 5-FU is often administered in combination with other chemotherapeutic agents, such as oxaliplatin or irinotecan. Moreover, molecularly targeted therapies against epidermal growth factor receptor (such as cetuximab) and vascular endothelial growth factor (such as bevacizumab) have also shown promising

effects in CRC. ${ }^{6,7}$ However, despite the increasing therapeutic options, drug resistance remains a major problem for the treatment of this disease. As the ultimate goal of cytotoxic chemotherapies is to induce death of tumour cells, the presence of an imbalance between functional and decoy TRAIL receptors may be one of the mechanisms involved in the 
development of drug resistance. Preclinical data have shown that the use of TRAIL in combination with chemotherapeutic agents, such as 5-FU, CPT-11 or doxorubicin, sensitises CRC cells to apoptosis ${ }^{8,9}$, possibly through over-expression of TRAIL-R2. ${ }^{10}$ Conversely, over-expression of TRAIL-R3 or -R4 has been correlated with resistance to apoptosis. ${ }^{11,12}$ Therefore, in vivo analysis of TRAIL receptors' expression in CRC tumour samples might be of clinical relevance. To this aim we analysed, using tissues micro arrays, TRAIL-R1 to -R4 expression in metastatic $\mathrm{CRC}$ of patients treated with 5-FU based chemotherapy as first line treatment. We then correlated these findings with response to treatment, disease progression and survival. 


\section{Patients and methods}

\subsection{Patients and treatment}

For this study, we selected 60 patients with metastatic CRC who were enrolled in controlled trials to evaluate the effect of first-line 5-FU-based chemotherapy at the CRLC Val d'AurellePaul Lamarque Cancer Centre in Montpellier, France, between 1991 and 2002. All our patients had a histological diagnosis of advanced colorectal adenocarcinoma with hepatic metastases either at the time of the diagnosis (i.e., synchronous disease) or after resection of the primary tumour (i.e., metachronous disease), and underwent surgery for primary CRC and/or hepatic metastases. Patients' and tumours' characteristics are summarised in Table 1. The age range was between 35 and 80 years (median 63 years). Thirty-six patients were males (60\%) and 24 females (40\%). Median follow-up was 78 months (range $1.6-146$ months). We excluded from this study any patient previously treated with radiotherapy.

All patients received a first-line 5-FU based regimen modulated by folinic acid. Specifically, 42 patients were treated with LV5FU2, 12 with FUFOL and 2 with capecitabine. The bimonthly LV5FU2 regimen was administered during 2 consecutive days as a 2-hour infusion of leucovorin $\left(200 \mathrm{mg} / \mathrm{m}^{2}\right)$ followed by a 5 -FU bolus $(400 \mathrm{mg} / \mathrm{m} 2)$ and a 22 -hour continuous infusion of 5 -FU $\left(600 \mathrm{mg} / \mathrm{m}^{2}\right)$. In the monthly FUFOL regimen, leucovorin $\left(200 \mathrm{mg} / \mathrm{m}^{2}\right)$ was administered as a $15-\mathrm{min}$ infusion followed by a 5 -FU bolus $\left(400 \mathrm{mg} / \mathrm{m}^{2}\right)$ over15 $\mathrm{min}$ administered during 5 consecutive days every 28 days. The treatment schedule was repeated every 3 weeks until appearance of disease progression, severe toxicity or death. Treatment evaluation was performed every 3 months by computer tomography scanner for tumour response and every cycle for toxicity. Patients were considered evaluable for response if they had received at least 3 chemotherapy cycles. Following standard World Health Organization (WHO) criteria ${ }^{13}$ we classified their clinical response into one of the following categories: complete response (CR), partial response (PR), stable disease (SD) and progressive disease 
(PD). We observed an objective response $(\mathrm{CR}+\mathrm{PR})$ in $19(32 \%)$ patients, $\mathrm{SD}$ in 21 patients $(35 \%)$ and $\mathrm{PD}$ in $20(33 \%)$. We then subdivided our population in two groups, nonprogressive $(\mathrm{CR}+\mathrm{PR}+\mathrm{SD})$ and progressive $(\mathrm{PD})$, for further analyses.

\subsection{Tissue Micro Array (TMA) construction}

Initially we selected tissue blocks which appeared to have enough material upon macroscopic inspection and stained some sections with haematoxylin-eosin to check for the presence of cancer tissue. Thus, we could mark, on each donor block, areas with primitive and/or metastatic CRC. From these selected areas we sampled, using a manual arraying instrument (Beecher Instrument, MTA1), 0.6-mm tissue cores that were used to construct two tissue micro arrays. The sampling consisted of three malignant cores from different areas of a single primitive and/or metastatic $\mathrm{CRC}$ that were placed at specific coordinates. After the arraying was completed, we cut $4 \mu \mathrm{m}$ sections from each TMA block, and stained with haematoxylineosin one section to confirm the presence of tumour tissue within each spot. The spots of 53 primary CRC and 33 hepatic metastases had enough material to assess the expression of the TRAIL receptors and only 5 patients out of 60 had insufficient material on both TMA blocks. In these cases we used classical sections for immuno-histochemistry.

\subsection{Immuno-histochemistry}

We deparaffinised and rehydrated through graded ethanol solutions adjacent $4 \mu \mathrm{m}$ sections that were then immersed sodium citrate buffer $(10 \mathrm{mM}, \mathrm{pH} 6)$ at ${ }^{\circ} \mathrm{C}$ for $40 \mathrm{~min}$ for epitope retrieval. After neutralisation of the endogenous peroxidase activity with $3 \%$ hydrogen peroxidase in methanol for $15 \mathrm{~min}$, we incubated the sections with primary antibodies against the four TRAIL receptors for $90 \mathrm{~min}$ and then visualised the binding with DAKO Liquid 
$\mathrm{LSAB}+$ following the manufacturer's recommendations (Dako, Glostrup, Denmark) using the Dako autostainer (Dako, Glostrup, Denmark). We purchased anti-human TRAIL-R1 (clone AF347, 1:10 dilution), anti-human TRAIL-R3, (clone AF630, 1:20 dilution) and anti-human TRAIL-R4 (clone AF633, 1:100 dilution) from RnD Systems (Minneapolis, USA), and antihuman TRAIL-R2 (clone ALX-210-743, 1:10 dilution) from Alexis (Switzerland). The specificity of these antibodies has been previously assessed by immunohistochemistry ${ }^{14-16}$, by FACS ${ }^{17}$ or by Western Blot. ${ }^{18}$ We used diaminobenzidine (DAB, Dako) as chromogen and lightly counterstained sections with haematoxylin. Sections incubated only with the appropriate secondary antibody were used as negative controls.

\subsection{Immuno-staining evaluation}

We ranked each spot according to the percentage of positive cells from 10 to $100 \%$. Continuous variables were subdivided into three equally-spaced quantiles $(<33 \%$ : low, 33$66 \%$ : medium, $>66 \%$ : high) that corresponded to the percentage of positive cells for each TRAIL receptor, whatever the intensity. Staining was separately evaluated for each spot. For triplicate cores, data were consolidated into a single score: the percentage value corresponded to the mean of the percentages of the three spots. The pathologist who scored the specimens was blinded to all clinical information.

\subsection{Statistical considerations}

All information relating to patient characteristics, treatment, clinical and pathological factors, response to therapy and outcome were collected. Categorical variables were reported by frequencies and percentages. Univariate statistical analyses were performed using Pearson's Chi-2 test or Fisher's exact test if applicable. Survival time was measured as the time from the 
beginning of chemotherapy to death. Patients alive at the time of analysis were censored at their last follow-up examination. Progression-free survival (PFS) was evaluated as the time from the beginning of chemotherapy up to progression or recurrence of the disease or death due to any cause. Survival rates were estimated according to the Kaplan-Meier method and the log rank test was used to assess differences between groups. Multivariate analyses for response to chemotherapy were performed by logistic regression using a backward stepwise selection procedure in order to evaluate the adjusted effects of the different variables. Cox's proportional hazards regression model using a backward stepwise selection procedure was used to investigate the impact of prognostic factors on PFS. All $p$ values reported were twosided. For all statistical tests, differences were considered significant at the $5 \%$ level. Statistical analyses were performed using the STATA 9.0 software. 


\section{Results}

\subsection{TRAIL receptors' expression in primary CRC and hepatic metastases}

In primary CRC and hepatic metastases, the four TRAIL receptors were localised mainly in the cytoplasm (Figure 1A) and their expression was quite variable among the different samples. Therefore, we decided to rank our samples in three different classes (low, medium and high) according to the number of positive cells for each TRAIL receptor (Figure 1B). We then looked at the distribution of the three classes (Figure 2) and observed that, in both primary CRC and hepatic metastases, the decoy receptor TRAIL-R4, was more often classified as highly expressed than the pro-apoptotic TRAIL-R1 $(\mathrm{p}<0.0001)$ and TRAIL-R2 ( $p<0.002$ and $p<0.014$ for primary CRC and HM respectively).

\subsection{TRAIL receptors' expression and clinico-pathological data}

As the patient cohort was relatively small, we chose to consider only two groups (i.e., low and medium TRAIL receptors' expression versus high TRAIL receptors' expression) in order to provide a stronger statistical power.

We did not find any significant association between the level of expression of each TRAIL receptor and age, gender, tumour site, tumour size or number of involved lymph nodes by univariate analysis. However, patients with low/medium TRAIL-R1 expression showed progressive disease (PD) during 5-FU-based chemotherapy more frequently than those with high TRAIL-R1 expression ( $45 \%$ vs $19 \%, p=0.052$ ). We did not identify any other univariate association between TRAIL receptors' expression and PD, progression-free survival (PFS) or overall survival. 
We then carried out a multivariate analysis to evaluate the effect of TRAIL receptors' expression, age, gender, tumour site, tumour size and number of lymph nodes on the response to chemotherapy and PFS. We did not find any correlation between low/medium or high TRAIL receptors' expression and objective response $(\mathrm{CR}+\mathrm{PR})$ to chemotherapy. However, when we compared progressive $(\mathrm{PD})$ and non-progressive status $(\mathrm{CR}+\mathrm{PR}+\mathrm{SD})$, we found that there was a significant higher risk of progressive disease in patients with concomitant low/medium TRAIL-R1 $(\mathrm{OR}=8.95 ; p=0.01)$ and high TRAIL-R3 expression $(\mathrm{OR}=5.38 ; p$ $=0.034$ ). Indeed, $70 \%$ of patients with low or medium TRAIL-R1 and high TRAIL-R3 expression developed progressive disease. Therefore, concomitant low/medium TRAIL-R1 and high TRAIL-R3 expression in primary CRC might represent a good predictor of non response to chemotherapy.

We obtained similar results for PFS, with hazard ratios of $2.48(p=0.011)$ in patients with low/medium TRAIL-R1 and $2.33(\mathrm{p}=0.015)$ in those with high TRAIL-R3, respectively (Table 2), but did not observe any association between TRAIL receptors' expression and overall survival.

These results allowed us to construct a prognostic index (PI) which categorised patients into three prognostic groups (good, intermediate and poor) by multiplying the hazard ratios of each category. Accordingly, concomitant low/medium TRAIL-R1 and high TRAIL-R3 expression resulted in a hazard ratio of $2.48 * 2.33=5.78$ and was associated with poor prognosis. The association of high TRAIL-R1 and low/medium TRAIL-R3 expression (reference category with a hazard ratio equal to 1) was associated with good prognosis. The intermediate prognostic category had a hazard ratio of 2.33 for high TRAIL-1 and high TRAIL-3 expression, or hazard ratio of 2.48 for low/medium TRAIL-1 and low/medium TRAIL-3 expression. 
We then applied this PI to our patient cohort, and classified $8 \%$ of them into the good, $73 \%$ into the intermediate and $19 \%$ into the poor prognostic group. Accordingly, $0 \%$ of the good, $29 \%$ of the intermediate and $70 \%$ of patients of the poor prognostic group had PD during the first-line 5-FU chemotherapy (Table 3). Moreover, the poor prognostic group had a shorter median PFS than the intermediate/good prognostic group (3.1 months in comparison to 10.1 months; $p=0.0034$ ) (Figure 3). 


\section{Discussion}

Drug resistance remains a major issue in cancer treatment. In this study we explored the potential role of the expression level of the four TRAIL receptors in the response to 5-FU based chemotherapy in patients with metastatic CRC. Our results indicate that concomitant low/medium TRAIL-R1 and high TRAIL-R3 expression in primary CRC is significantly associated with a poor response to 5-FU based first line chemotherapy and with shorter progression-free survival. Then, by combining the levels of expression of TRAIL-R1 and TRAIL-R3, we constructed a prognostic index that allowed us to evaluate the risk of disease progression in our patients. To the best of our knowledge this is the first study showing the clinical relevance of both TRAIL-R1 and -R3 expression in stage IV CRC.

Controversial findings have been reported on the prognostic significance of TRAIL-R1 in CRC. A recent prospective study has shown an association between high TRAIL-R1 expression and shorter disease-free as well as overall survival time in stage III adjuvanttreated CRC patients. ${ }^{19}$ On the contrary, another study demonstrated that high TRAIL-R1 expression is associated with a longer disease-free survival after curative resection of stage II and III CRC ${ }^{20}$. Several factors may account for the discrepancies between these studies, including differences in patients' group studied, in antibody sensitivities and in the grading system used to assess immunoreactivity. Strater and colleagues, ${ }^{20}$ suggested that TRAIL-R1 expression could be useful to predict the response to adjuvant chemotherapy. This finding is consistent with our results and together they suggest that high expression of pro-apoptotic TRAIL-R1 is linked to a greater apoptotic potential in a therapeutic setting.

TRAIL-R1 and TRAIL-R2 have been studied in many malignant tumours, notably cervical and oesophageal carcinomas, because they are functional receptors of the apoptotic pathway and, therefore, potential therapeutic targets. ${ }^{21-23}$ However, the decoy receptors TRAIL-R3 and TRAIL-R4 might also be important to predict the response and to explain the possible 
resistance to a certain treatment. ${ }^{12,24}$ Preclinical data have shown that TRAIL-R3 has a role in the protection of either normal or tumour cells through the induction of survival-signalling pathways or of altered apoptotic signals. ${ }^{25-27}$

Resistance to apoptosis has been evoked as a possible mechanism to explain the therapeutic failure of fluoropyrimidines. Indeed, it has been shown that silencing of the death-inducing TRAIL-R2 in tumours confers resistance to $5-\mathrm{FU} .{ }^{28}$ On the other hand, 5-FU resistance in CRC cell lines could be overcome by inhibiting expression of the decoy TRAIL-R3 (manuscript in preparation). Moreover, the extracellular domains of both decoy and deathinducing TRAIL receptors can interact in a ligand-independent manner suggesting that preligand assembly may account for the inhibitory effects of TRAIL-R3 and TRAIL-R4 in certain cell types. ${ }^{29}$ Similarly, Clancy and colleagues, showed that inhibition of apoptosis depends on the formation of ligand-independent complexes between TRAIL-R2 and TRAILR4. ${ }^{30}$ Taken together these results emphasise the role and the interaction of death and decoy TRAIL-receptors and their possible implication in resistance to 5-FU chemotherapy.

New and reliable prognostic and predictive markers for CRC response to treatment are required. Many proteins involved in different aspects of tumour development and treatment response have been extensively studied, including $\mathrm{p} 53$, metabolic enzymes and MMR (mismatch repair) proteins that play a role in microsatellite instability. ${ }^{31,32}$ However, none of them is currently used or validated for routine chemotherapeutic management of patients. Our results demonstrate the clinical relevance of TRAIL-R1 and -R3 expression as predictive and prognostic marker in patients with metastatic CRC treated with 5FU-based chemotherapy. However, before using TRAIL-R1 and -R3 expression as a predictor for individually targeted therapy, our results need to be validated in prospective studies that will include a larger number of patients. Indeed, a methodical analysis of the expression level of the pro-apoptotic TRAIL-R1 in a variety of tumours could be interesting, considering the promising results 
obtained in preclinical studies and phase I/II clinical trials with antibodies targeting TRAIL$\mathrm{R} 1{ }^{33}$

\section{Conflict of interest statement}

None declared.

\section{Acknowledgements}

This work was supported by the French Ministry of Health (Programme Hospitalier de

Recherche Clinique - PHRC Régional 2003). 


\section{References}

1. Pan G, O'Rourke K, Chinnaiyan AM, et al. The receptor for the cytotoxic ligand TRAIL. Science 1997;276:111-3.

2. Ashkenazi A, Pai RC, Fong S, et al. Safety and antitumor activity of recombinant soluble Apo2 ligand. J Clin Invest 1999;104:155-62.

3. Gliniak B, Le T. Tumor necrosis factor-related apoptosis-inducing ligand's antitumor activity in vivo is enhanced by the chemotherapeutic agent CPT-11. Cancer Res 1999;59:6153-8.

4. de Vries EG, Gietema JA, de Jong S. Tumor necrosis factor-related apoptosis-inducing ligand pathway and its therapeutic implications. Clin Cancer Res 2006;12:2390-3.

5. Duiker EW, Mom CH, de Jong S, et al. The clinical trail of TRAIL. Eur J Cancer 2006; 42:2233-40.

6. Cunningham D, Humblet $Y$, Siena $S$, et al. Cetuximab monotherapy and cetuximab plus irinotecan in irinotecan-refractory metastatic colorectal cancer. $N$ Engl J Med 2004;351:337-45.

7. Hurwitz H, Fehrenbacher L, Novotny W, et al. Bevacizumab plus irinotecan, fluorouracil, and leucovorin for metastatic colorectal cancer. N Engl J Med 2004;350:2335-42.

8. Naka T, Sugamura K, Hylander BL, Widmer MB, Rustum YM, Repasky EA. Effects of Tumor Necrosis Factor-related Apoptosis-inducing Ligand Alone and in Combination with Chemotherapeutic Agents on Patients' Colon Tumors Grown in SCID Mice. Cancer Res 2002;62:5800-6.

9. Shimoyama S, Mochizuki Y, Kusada O, Kaminishi M. Supra-additive antitumor activity of $5 \mathrm{FU}$ with tumor necrosis factor- related apoptosis-inducing ligand on gastric and colon cancers in vitro. Int J Oncol 2002;21:643-8.

10. Arts HJ, de Jong S, Hollema H, ten Hoor K, van der Zee AG, de Vries EG. Chemotherapy induces death receptor 5 in epithelial ovarian carcinoma. Gynecol Oncol 2004;92:794800 .

11. Bernard D, Quatannens B, Vandenbunder B, Abbadie C. Rel/NF-kappaB transcription factors protect against tumor necrosis factor (TNF)-related apoptosis-inducing ligand (TRAIL)-induced apoptosis by up-regulating the TRAIL decoy receptor DcR1. J Biol Chem 2001;276:27322-8.

12. Sanlioglu AD, Dirice E, Aydin C, Erin N, Koksoy S, Sanlioglu S. Surface TRAIL decoy receptor-4 expression is correlated with TRAIL resistance in MCF7 breast cancer cells. BMC Cancer 2005;5:54.

13. Miller AB, Hoogstraten B, Staquet M, Winkler A. Reporting results of cancer treatment. Cancer 1981;47:207-14.

14. van Geelen CM, Westra JL, de Vries EG, et al. Prognostic significance of tumor necrosis factor-related apoptosis-inducing ligand and its receptors in adjuvantly treated stage III colon cancer patients. J Clin Oncol 2006;24:4998-5004.

15. Hueber A, Aduckathil S, Kociok N, et al. Apoptosis-mediating receptor-ligand systems in human retinal pigment epithelial cells. Graefes Arch Clin Exp Ophthalmol 2002;240:551-6.

16. Sanlioglu AD, Dirice E, Elpek O, et al. High levels of endogenous tumor necrosis factorrelated apoptosis-inducing ligand expression correlate with increased cell death in human pancreas. Pancreas 2008;36:385-93 
17. Sanlioglu AD, Korcum AF, Pestereli E, et al. TRAIL death receptor-4 expression positively correlates with the tumor grade in breast cancer patients with invasive ductal carcinoma. Int J Radiat Oncol Biol Phys 2007;69:716-23.

18. Schon MP, Wienrich BG, Drewniok C, et al. Death receptor-independent apoptosis in malignant melanoma induced by the small-molecule immune response modifier imiquimod. J Invest Dermatol 2004;122:1266-76.

19. Mundt B, Wirth T, Zender L, et al. Tumour necrosis factor related apoptosis inducing ligand (TRAIL) induces hepatic steatosis in viral hepatitis and after alcohol intake. Gut 2005;54:1590-6.

20. Strater J, Hinz U, Walczak H, et al. Expression of TRAIL and TRAIL receptors in colon carcinoma: TRAIL-R1 is an independent prognostic parameter. Clin Cancer Res 2002;8:3734-40.

21. Reed JC. Apoptosis-targeted therapies for cancer. Cancer Cell 2003;3(1):17-22.

22. Reesink-Peters N, Hougardy BM, van den Heuvel FA, et al. Death receptors and ligands in cervical carcinogenesis: an immunohistochemical study. Gynecol Oncol 2005;96:705-13

23. Younes M, Georgakis GV, Rahmani M, Beer D, Younes A. Functional expression of TRAIL receptors TRAIL-R1 and TRAIL-R2 in esophageal adenocarcinoma. Eur $J$ Cancer 2006; 42:542-7.

24. Riccioni R, Pasquini L, Mariani G, et al. TRAIL decoy receptors mediate resistance of acute myeloid leukemia cells to TRAIL. Haematologica 2005;90:612-24.

25. Merino D, Lalaoui N, Morizot A, Schneider P, Solary E, Micheau O. Differential inhibition of TRAIL-mediated DR5-DISC formation by decoy receptors 1 and 2. Mol Cell Biol 2006;26:7046-55.

26. Secchiero P, Gonelli A, Carnevale E, et al. TRAIL promotes the survival and proliferation of primary human vascular endothelial cells by activating the Akt and ERK pathways. Circulation 2003;107:2250-6.

27. Sheridan JP, Marsters SA, Pitti RM, et al. Control of TRAIL-induced apoptosis by a family of signaling and decoy receptors. Science 1997;277:818-21.

28. Wang S, El-Deiry WS. Inducible silencing of KILLER/DR5 in vivo promotes bioluminescent colon tumor xenograft growth and confers resistance to chemotherapeutic agent 5-fluorouracil. Cancer Res 2004;64:6666-72.

29. Chan FK. Three is better than one: pre-ligand receptor assembly in the regulation of TNF receptor signaling. Cytokine 2007;37:101-7.

30. Clancy L, Mruk K, Archer K, et al. Preligand assembly domain-mediated ligandindependent association between TRAIL receptor 4 (TR4) and TR2 regulates TRAILinduced apoptosis. Proc Natl Acad Sci U S A 2005;102:18099-104.

31. Benatti P, Gafa R, Barana D, et al. Microsatellite instability and colorectal cancer prognosis. Clin Cancer Res 2005;11:8332-40.

32. Etienne MC, Chazal M, Laurent-Puig P, et al. Prognostic value of tumoral thymidylate synthase and p53 in metastatic colorectal cancer patients receiving fluorouracil-based chemotherapy: phenotypic and genotypic analyses. J Clin Oncol 2002;20:2832-43.

33. Pukac L, Kanakaraj P, Humphreys R, et al. HGS-ETR1, a fully human TRAIL-receptor 1 monoclonal antibody, induces cell death in multiple tumour types in vitro and in vivo. Br J Cancer 2005;92:1430-41. 


\section{Figure legends}

Figure 1 A. Localisation of TRAIL receptors (original magnification x 400). B. Expression pattern of the four TRAIL receptors in tissue micro arrays of primary CRC. Immunohistochemical staining classes were defined as following: low $<33 \%$, medium $33 \%-66 \%$ and high $>66 \%$ cells expressing that receptor (original magnification x100). C. Negative control: section was incubated only with the appropriate secondary antibody.

Figure 2 Distribution of TRAIL receptors' immunostaining classes in primary CRC (pCRC) and hepatic metastases (HM). Expression of each TRAIL receptor was indicated as following: low (black), medium (grey) and high (white).

Figure 3 Kaplan-Meier curves of PFS in metastatic CRC patients according to the prognostic index : poor (----) versus intermediate/good (-) prognostic groups. 
Table 1. Clinico-pathological characteristics

\begin{tabular}{|c|c|c|}
\hline Characteristics & $n$ & $\%$ \\
\hline \multicolumn{3}{|l|}{ Age } \\
\hline$<60$ & 25 & 42 \\
\hline$\geq 60$ & 35 & 58 \\
\hline \multicolumn{3}{|l|}{ Gender } \\
\hline Male & 36 & 60 \\
\hline Female & 24 & 40 \\
\hline \multicolumn{3}{|l|}{ pT stage } \\
\hline pT2 & 4 & 7 \\
\hline pT3 & 39 & 65 \\
\hline pT4 & 17 & 28 \\
\hline \multicolumn{3}{|l|}{ pN stage } \\
\hline 0 & 14 & 23 \\
\hline 1 & 22 & 37 \\
\hline 2 & 21 & 35 \\
\hline missing & 3 & 5 \\
\hline \multicolumn{3}{|l|}{ Synchronous metastases } \\
\hline yes & 42 & 70 \\
\hline no & 18 & 30 \\
\hline \multicolumn{3}{|l|}{ Tumour Site } \\
\hline colon & 51 & 85 \\
\hline rectum & 9 & 15 \\
\hline \multicolumn{3}{|l|}{ Chemotherapy regimen } \\
\hline LV5FU2 & 46 & 77 \\
\hline FUFOL & 12 & 20 \\
\hline Capecitabine & 2 & 3 \\
\hline \multicolumn{3}{|l|}{ Response } \\
\hline Complete Response & 1 & 2 \\
\hline Partial Response & 18 & 30 \\
\hline Stable Disease & 21 & 35 \\
\hline Progressive Disease & 20 & 33 \\
\hline
\end{tabular}


Table 2. Progressive disease during chemotherapy and progression-free survival according to TRAIL-R1 and -R3 expression in patients treated with 5FU-based first line chemotherapy.

\begin{tabular}{cccc}
\hline Progressive disease & Odds ratio & $\mathbf{9 5 \%}$ CI & $\boldsymbol{p}$ \\
\hline Low/medium TRAIL-R1 & 8.95 & $1.69-47.43$ & 0.010 \\
High TRAIL-R3 & 5.38 & $1.13-25.57$ & 0.034 \\
\hline Progression-free survival & Hazard ratio & $\mathbf{9 5 \%}$ CI & $\boldsymbol{p}$ \\
Low/medium TRAIL-R1 & 2.48 & $1.22-5.01$ & 0.011 \\
High TRAIL-R3 & 2.33 & $1.18-4.63$ & 0.015 \\
\hline
\end{tabular}


Table 3 Progressive disease during first-line 5-FU-based chemotherapy according to the prognostic index

\begin{tabular}{lcc}
\hline $\begin{array}{l}\text { Prognostic } \\
\text { index* }\end{array}$ & Number of patients & Progressive patients \\
\hline Good & 4 & $0(0 \%)$ \\
& 38 & $11(29 \%)$ \\
Intermediate & 10 & $7(70 \%)$ \\
Poor & 52 & 18 \\
\hline Total & \\
\hline $\begin{array}{l}\text { * Good = high TRAIL-1 and low/medium TRAIL-3; Poor }=\text { low/medium TRAIL-1 } \\
\text { and high TRAL-3; Intermediate }=\text { concordant TRAIL-1 and }-3 \text { expression (both high } \\
\text { or both low/medium) }\end{array}$
\end{tabular}


Figure 1
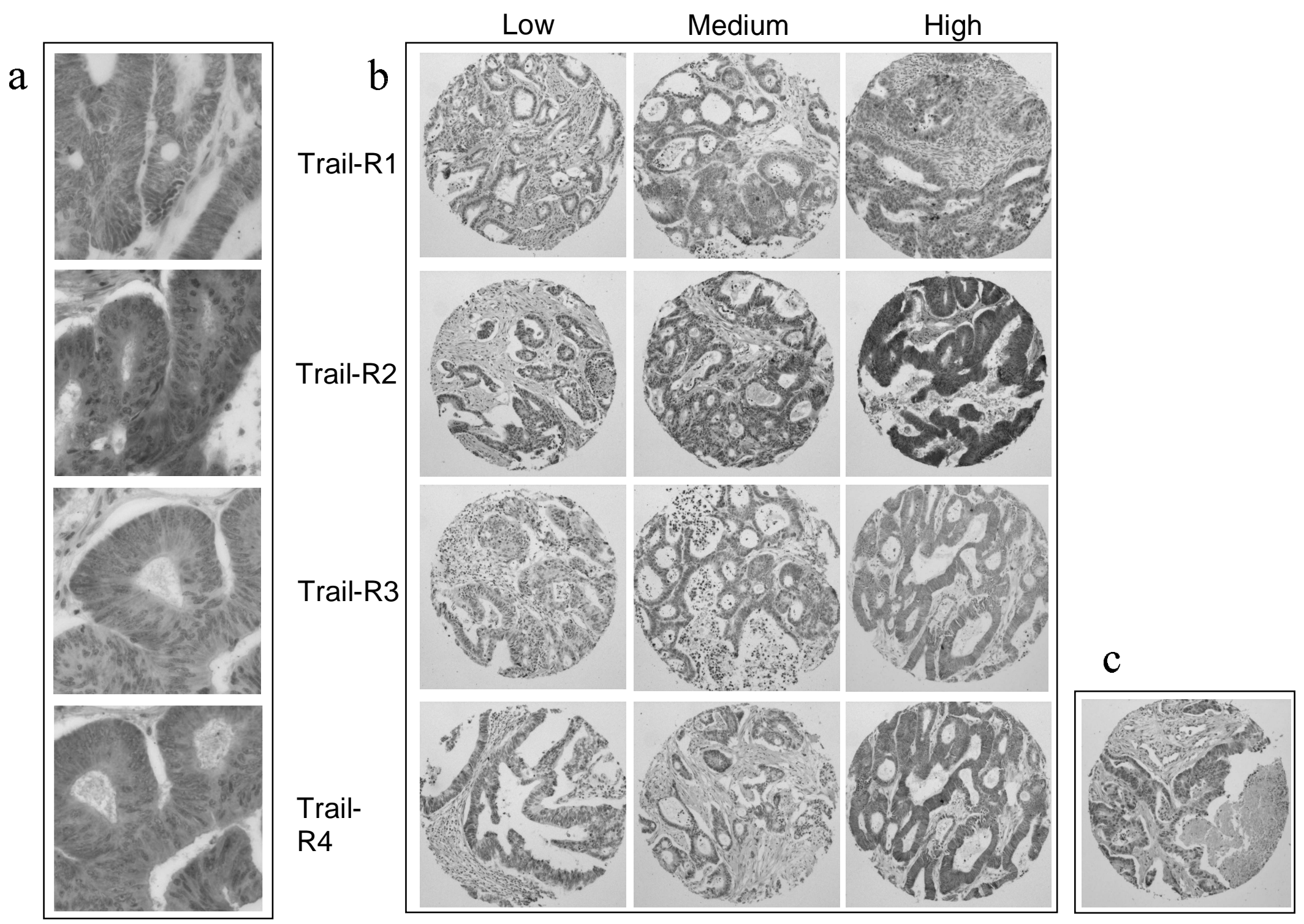
Figure 2

$$
\text { - Low } \square \text { Medium } \square \text { High }
$$

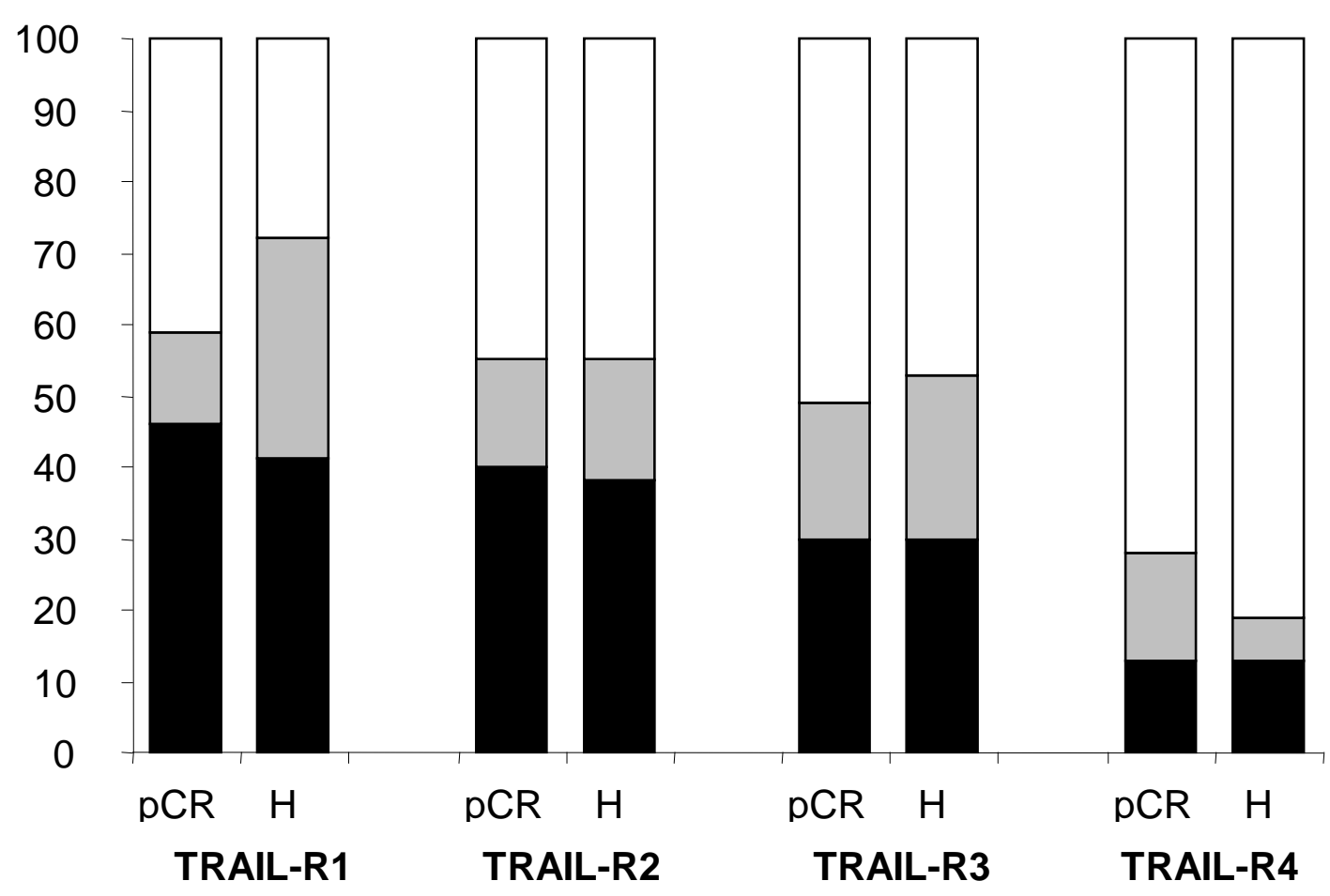


Figure 3

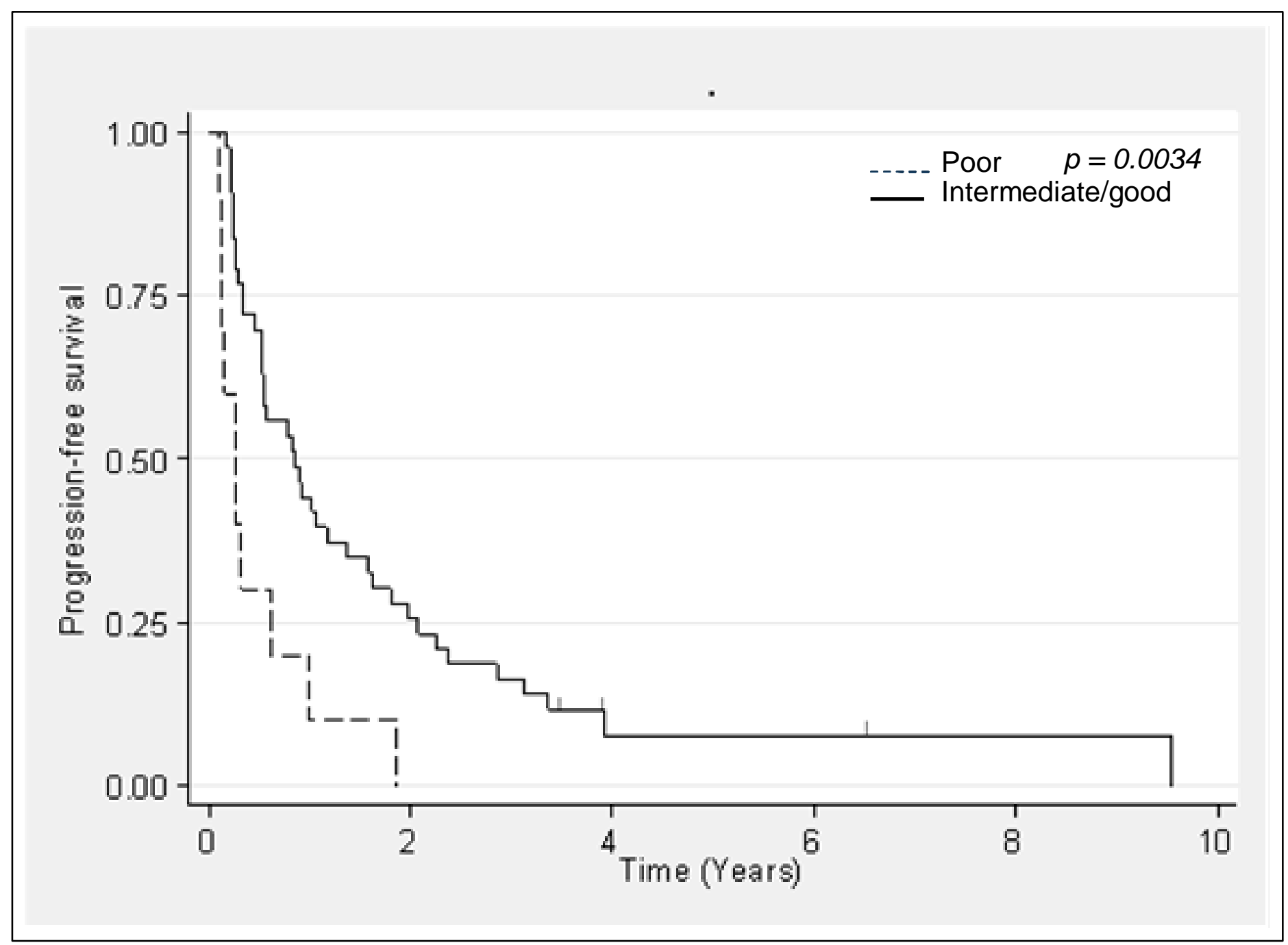


